\title{
Significant adverse reactions to long-acting gonadotropin-releasing hormone agonists for the treatment of central precocious puberty and early onset puberty
}

\author{
Ji Woo Lee, MD', \\ Hyung Jin Kim, MD', \\ Yun Mee Choe, $\mathrm{MD}^{2}$, \\ Hee Suk Kang, RN ${ }^{1}$, \\ Soon Ki Kim, MD', \\ Yong Hoon Jun, MD', \\ Ji Eun Lee, MD'
}

Department of ${ }^{1}$ Pediatrics and ${ }^{2}$ Surgery, Inha University Hospital, Grauduate School of Medicine, Inha University, Incheon, Korea
Received: 8 August, 2014

Revised: 6 September, 2014

Accepted: 20 September, 2014

Address for correspondence:

Ji Eun Lee, MD

Department of Pediatrics, Inha University Hospital, Grauduate School of Medicine, Inha University, of Medicine, 27 Inhang-ro, Jung-gu, Incheon 400-711, Korea

Tel: +82-32-890-3617

Fax: +82-32-890-2844

E-mail: anicca@inha.ac.kr
Purpose: Long-acting gonadotropin-releasing hormone agonists ( $\mathrm{GnRHa}$ ) are commonly used to treat central precocious puberty (CPP) in Korea. Although rare, there have been reports on the characteristic of adverse reactions of GnRHa in CPP among the Korean population. This study was intended to report on our clinical experience regarding significant adverse reactions to long-acting GnRHa in CPP and early onset puberty and to evaluate the prevalence rate of serious side effects. Methods: This retrospective study included children with CPP and early onset puberty, who were administered monthly with long-acting GnRHa (leuprolide acetate, triptorelin acetate) at the outpatient clinic of Department of Pediatrics, at Inha University Hospital, between January 2011 and December 2013. We analyzed the clinical characteristics of patients who experienced significant adverse reactions and evaluated the prevalence rate.

Results: Six serious side effects (0.9\%) were observed among total of 621 CPP and early onset puberty children with GnRHa therapy. The number of sterile abscess formation was four in three patients (4 events of 621). Anaphylaxis occurred in only one patient, and unilateral slipped capital femoral epiphysis (SCFE) in another one patient. Anaphylaxis occurred after the 6 th administration of the monthly depot triptorelin acetate. Unilateral SCFE developed in GnRHa therapy.

Conclusion: Sterile abscess formation occurred in $0.6 \%$ of CPP and early onset puberty patients from the administration of a monthly depot GnRHa therapy. The occurrences of anaphylaxis and SCFE are extremely rare, but can have serious implications on patients. Clinicians should be aware of these potential adverse effects related to GnRHa therapy in CPP.

Keywords: Drug-related side effects and adverse reactions, Central precocious puberty, Leuprolide, Triptorelin

\section{Introduction}

Precocious puberty is defined as the occurrence of sexual maturation before the age of 8 years in girls and 9 years in boys. Central precocious puberty (CPP) is the gonadotropindependent form induced by the premature activation of the hypothalamic-pituitary-gonadal axis, due to various causes. The global secular decline in age at puberty has been recently reported with an increase in the number of children with CPP worldwide ${ }^{1,2)}$.

Long-acting gonadotropin-releasing hormone agonists (GnRHa) are considered as a treatment for choice for pediatric CPP. Prolonged administration of GnRHa suppresses the pituitary-gonadal axis activity with a subsequent decrease of sex hormones. In Korea, monthly 
formulation of GnRHa, such as leuprolide acetate depot and triptorelin acetate depot, are widely used in children with CPP. The number of children treated with CPP using these drugs has gradually increased due to an increase in the number of girls referred for evaluation of $\mathrm{CPP}^{3)}$.

Although local side effects, including pain, flares and subcutaneous nodules have been known, long-acting formulations of GnRHa are well tolerated in children. However, sterile abscess formation related to GnRHa can be one of the most significant adverse drug reactions that greatly affect the compliance with the treatment. Sterile abscess formation has been generally reported as $1.5 \%-3 \%$ of all patients with monthly depot GnRHa therapy ${ }^{4,5}$; however, there have been no reports of an incidence of sterile abscess in Korea yet, despite there being a case report in $2 \mathrm{CPP}$ children ${ }^{6}$. Meanwhile, anaphylaxis may rarely occur as a systemic side effect related to GnRHa administration. Recently, there have been reports indicating that administration of GnRHa may be a risk factor for the development of slipped capital femoral epiphysis (SCFE) ${ }^{7-10)}$.

The purpose of this study was intended to report our clinical experience with significant adverse reactions to long-acting GnRHa in CPP at single pediatric tertiary medical center and to evaluate the prevalence rate of serious side effects.

\section{Materials and methods}

This study was conducted to report on those patients who experienced severe adverse effects among the total CPP and early onset puberty patients who were administered monthly long-acting GnRHa (leuprolide acetate, triptorelin acetate) at the outpatient clinic at Department of Pediatrics, Inha University Hospital, from January 2011 to December 2013. We analyzed the clinical characteristics of patients who experienced significant adverse reactions and evaluated the prevalence rate.

The subjects' medical records were reviewed retrospectively. Information regarding gender, age, height, weight, pubertal stage, bone age, serum hormone levels including luteinizing hormone (LH), follicle-stimulating hormone (FSH), and estradiol (E2) were recorded. In addition, drug type of GnRHa used for therapy, injection dose and interval, onset of occurrence of adverse reaction, clinical course of adverse reaction, and past allergy history were recorded.

The definitions of terms are as follows. CPP is the onset of signs of puberty before the age of 8 years in girls and 9 years in boys, the result of early maturation of the hypothalamicpituitary-gonadal axis. Early onset puberty is defined as the occurrence of sexual maturation after the age of 8 years and before 9 years in girls, after 9 years and before 10 years in boys. Sterile abscess is defined as an abscess with contents that are not caused by pyogenic bacteria. Anaphylaxis is a serious allergic or hypersensitivity reaction that is rapid in onset and may cause life- threatening conditions ${ }^{11)}$. SCFE is the displacement of the upper femoral epiphysis from the femoral metaphysis ${ }^{10}$.

\section{Results}

Among the total 621 patients, 469 girls ( $8.78 \pm 0.45$ years) were treated with monthly depot leuprolide acetate, of which, 152 girls $(8.35 \pm 0.47$ years $)$ were treated with monthly depot triptorelin acetate. Drug-related serious side effects were observed in 6 events within 5 girls among the total patients (0.9\%). In 4 events out of 621 patients, sterile abscess resulted from an administration of $\mathrm{GnRHa}$, which demonstrated $0.6 \%$ prevalence rate. Anaphylaxis happened in one patient, and unilateral SCFE in another patient relatively (Table 1).

\section{Four events in 3 cases of sterile abscess formation}

\section{1) Case 1}

This 7.6-year-old girl was an otherwise healthy diagnosed with CPP following presentation of an 8-month history of breast development (Tanner stage 3) with growth spurt. Her height was $130.3 \mathrm{~cm}$ (50th-75th percentile), and weight was $30 \mathrm{~kg}$ (50th75 th percentile). Her bone age was 10 years by the Greulich and Pyle method at a chronological age of 7.85 years. GnRH stimulation test demonstrated a dominant $\mathrm{LH}$ response; peak LH level, 7.5mIU/mL; peak FSH level, $8.2 \mathrm{mIU} / \mathrm{mL}$. Luprolide acetate depot (Leuplin, Takeda pharmaceuticals Korea, Seoul, Korea) therapy began with subcutaneously (SC) injection every 4 weeks. After the second injection, she had heat sensation at the injection site and a mass was formed. Following the seventh injection, erythematous plaques with sterile abscess (size: 15 $\mathrm{mm} \times 20 \mathrm{~mm}, 5 \mathrm{~mm} \times 5 \mathrm{~mm}$ ) were developed at the injection site after three weeks. The drug has been switched to triptorelin acetate depot (Decapeptyl, Ferring pharmaceuticals, Seoul, Korea) intramuscularly (IM) injection without further problems.

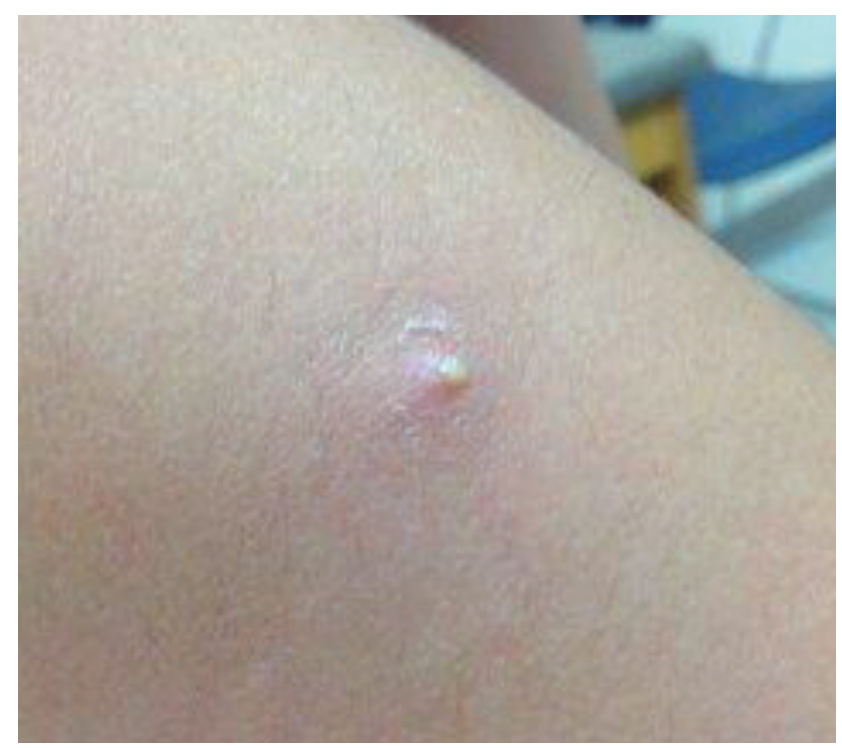

Fig. 1. Leuprolide acetate depot was subcutaneously injected into the upper arm of a 7.6-year- old girl at four-week interval. A sterile abscess was formed at the injection site after the 7th injection. 

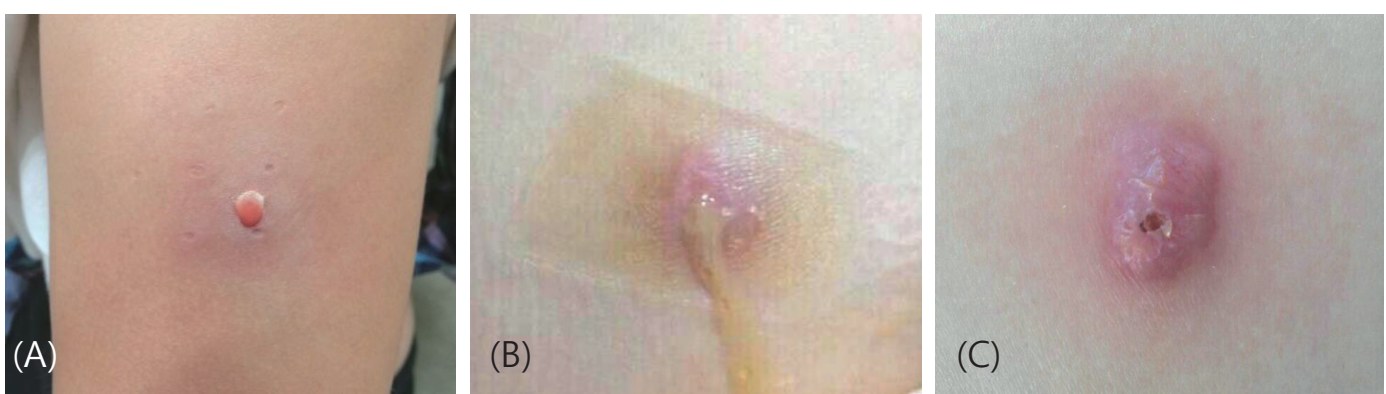

Fig. 2. Leuprolide acetate depot was subcutaneously injected into the arm of a 9-year-old girl at four-week interval. (A) A sterile abscess was formed at the injection site after the 5th injection. (B) The treatment was switched to triptorelin depot, which intramuscularly injected into her buttock, but a sterile abscess and pus formed 3 weeks after the first injection. (C) The lesion on the buttock healed with scarring 10 weeks later.

The abscess local lesion was healed after spontaneous rupture of abscess (Fig. 1).

\section{2) Case 2}

An 8.9-year-old girl was presented with 10 months of breast development (Tanner stage 3). Height was $134.3 \mathrm{~cm}$ (25th-50th percentile) and weight was $29.5 \mathrm{~kg}$ (25th-50th percentile), but an increase in growth velocity over 6 months showed. Random serum levels of $\mathrm{LH}, \mathrm{FSH}, \mathrm{E} 2$ were $2.4 \mathrm{mIU} / \mathrm{mL}$ (normal, $<0.3$ $\mathrm{mIU} / \mathrm{mL}$ ), $5.03 \mathrm{mIU} / \mathrm{mL}$ (normal, $1.0-4.2 \mathrm{mIU} / \mathrm{mL}$ ), and $45.18 \mathrm{pg} / \mathrm{mL}$ (normal, $<10 \mathrm{pg} / \mathrm{mL}$ ), respectively. Her bone age was advanced at 10 years. Leuprolide acetate depot (Luphere, Daewoong pharmaceutical, Seoul, Korea) initiated SC monthly injection. Following the ninth injection of leuprolide acetate depot SC, she developed a painful erythematous change at the injection site, consistent with sterile abscess. The lesion gradually healed without any scarring. After the therapy was changed to triptorelin acetate depot (Decapeptyl) IM injection, there has been no particular local site events.

\section{3) Case 3}

An otherwise healthy 9-year-old girl visited the hospital due to an 8 -month history of progressive breast development (Tanner stage 3) with pubic hair (Tanner stage 2): random LH, $1.8 \mathrm{mIU} / \mathrm{mL}$; FSH, $1.6 \mathrm{mIU} / \mathrm{mL}$ E2, $12.7 \mathrm{pg} / \mathrm{mL}$. Her height was $140.5 \mathrm{~cm}$ (75th-90th percentile), and weight was $41 \mathrm{~kg}$ (90th-95th percentile). Her bone age was 11 years. Luprolide acetate depot (Luphere) administered with a diagnosis with early onset puberty. After the fifth injection, a sterile abscess formation (size, $20 \mathrm{~mm} \times 15 \mathrm{~mm}$ ) with pus occurred at the injection site. Recurrent abscess developed and it was frequently drained from the injection site. Eight weeks later, the wound healed with little scarring. Thereafter, the treatment of drug was changed to triptorelin acetate depot (Decapeptyl), which was IM injected in the buttock. The injection therapy was stopped due to a sterile abscess with pus (size, $20 \mathrm{~mm} \times 15 \mathrm{~mm}$ ) that occurred again at the injection site after the first triptorelin acetate depot shot. The lesion on her buttock healed leaving a residual scarring (size, 10 $\mathrm{mm} \times 10 \mathrm{~mm}$ ) 10 weeks later (Fig. 2). She had clinically pubertal progression (Breast Tanner stage 4, pubic hair Tanner stage 3) after sterile abscess formation. Now her bone age is 13 years at a chronological age of 10.2 years.

\section{One case of anaphylaxis}

\section{1) Case 4}

An 8.4-year-old girl was presented with breast development (Tanner stages 2,3) and pubic hair (Tanner stage 2) over the preceding 10 months. She had neither a specific medical history nor history of allergic disorder. Her height was $135.7 \mathrm{~cm}$ (90th95th percentile), and weight was $31.4 \mathrm{~kg}$ (70th-90th percentile). Her bone age was 10 years. GnRH stimulation testing showed the diagnosis of early puberty with $\mathrm{LH}$ peaking at $32.6 \mathrm{mIU} /$ $\mathrm{mL}$ and $\mathrm{FSH}$ peaking at $28.5 \mathrm{mIU} / \mathrm{mL}$. She was treated with triptorelin acetate depot (Decapeptyl) SC injected at four-week intervals. Immediately after the sixth injection, she developed dizziness, headache, whole body redness, and chest tightness. Subsequently, she lost consciousness. Blood pressure (BP) could not be measured at that time. All of the above symptoms were relieved within several minutes without any particular treatment. Her BP measured after the recovery was $99 / 56 \mathrm{mmHg}$ which was a low-normal level (systolic, 25th-50th percentile; diastolic, 25 th-50th percentile). Her ordinary BP was $110 / 60 \mathrm{mmHg}$ (systolic, 50th-75th percentile; diastolic, 75th-90th percentile). Anaphylaxis was considered to have occurred, and the drug therapy was changed into a monthly SC injection of leuprolide acetate depot (Leuplin). She maintained this monthly leuprolide therapy without further systemic adverse reactions.

\section{One case of unilateral SCFE}

1) Case 5

A 9-year-old girl visited the hospital due to a 6-month history of progressive breast development (Tanner stage 3). She had no specific medical history. Her height was $140 \mathrm{~cm}$ (75th-90th percentile), weight was $38 \mathrm{~kg}$ (75th-90th percentile), and body mass index $z$-score was 85 th percentile. Her bone age was 11.5 years compared with chronological age of 9 years. Random serum levels of LH, FSH, and E2 were $0.82 \mathrm{mIU} / \mathrm{mL}, 1.12$ $\mathrm{mIU} / \mathrm{mL}$, and $12.5 \mathrm{pg} / \mathrm{mL}$, relatively. Leuprolide acetate depot 
(Luphere) was initiated at $3.75 \mathrm{mg}$ SC every four weeks, which was switched after the fifth injection to $3.75 \mathrm{mg}$ IM triptorelin acetate depot (Decapeptyl), every 4 weeks, due to painful erythematous change at the injection site. Following the sixth injection of triptorelin acetate depot, she experienced worsening limping and hip pain of the right side for 2 weeks. She was diagnosed with unilateral SCFE and immediately underwent in situ pinning surgery. The diagnosis and surgery for SCFE was performed at another hospital. The GnRHa therapy was discontinued.

\section{Discussion}

Neely et al. ${ }^{4)}$ published about a sterile abscess occurring after the use of GnRHa in pediatric patients with CPP for the first time in 1992. Thereafter, several cases of sterile abscess formations after GnRHa depot formulations have been reported in western countries ${ }^{12,13)}$. In Korea, Kim and Shin ${ }^{6)}$ reported two cases who have formed sterile abscesses during CPP treatment.

In this study, sterile abscesses formations occurred in $0.6 \%$ of CPP and early onset puberty patients with GnRHa therapy. Out of a total of 469 patients with leuprolide acetate depot, three events $(0.6 \%)$, while in one event $(0.6 \%)$ out of a total of 152 patients with triptorelin acetate depot. In the first and second cases, sterile abscess formation occurred under leuprolide acetate therapy, and abscess did not occur after being changed into triptorelin acetate. In case 3 , sterile abscesses not only occurred following leuprolide acetate depot therapy, but also developed even after a switch to another GnRHa, triptorelin acetate depot.

The postulated cause for these reactions is likely to be antibody formation against the biodegradable polymers, which deliver GnRHa drug in a long-acting manner, ${ }^{4,12,13)}$. It also thought to be an adverse reaction to the GnRHa peptide itself $^{12,13)}$. Particularly, leuprolide injection has much higher rates of reaction than other GnRHa. Otherwise, it has been speculated that drug injection into the more immunologically active and less vascular subdermis can induce the abscess reaction. The fact that our third case had sterile abscesses formation following treatment with 2 different long-acting GnRHa suggests that the cause may be the same type of biodegradable polymers (lactic acid glycolic acid copolymer) in the depots.

While sterile abscesses are rare, such reaction can induce great anxiety to patients and families. These reactions may often persist for several months and can leave significant scarring such as our third case. These formations can also cause the failure of GnRHa therapy. Also, these effects may determine treatment interruption. Clinicians should be aware of the chance of adverse reactions following the treatment of GnRHa depot.

There are several reports of anaphylaxis to GnRHa in Western countries. Grant and Levinson ${ }^{14)}$ published the case of an anaphylaxis to leuprolide acetate depot injection in a 66-yearold patient with prostate cancer. Luchinger et al. ${ }^{15)}$ report a case of a proven allergy to leuprolide acetate depot. There has been no report regarding anaphylaxis to GnRHa treatment in CPP yet in Korea. Among the database of International Drug Monitoring of the World Health Organization (WHO), reports of GnRHa and adverse effects on the immune system in 97 countries from 1988 to 2010 were shown in Table $2^{16)}$.

According to the guidelines for anaphylaxis published in 2006, anaphylaxis can be diagnosed if there are two or more symptoms, such as involvements of the skin-mucosal tissue, respiratory compromise, reduced BP or associated symptom, and persistent gastrointestinal symptoms after exposure to any allergen ${ }^{11)}$. In this case of 4 , two more symptoms occurred immediately after the sixth triptorelin acetate depot injection and fortunately reactions were relieved without any particular treatment. Although the occurrences of anaphylactic reactions to GnRHa are incidental and very rare, it can have serious implication in patients. Hence, managements against anaphylactic shocks should be recognized.

SCFE is an early adolescent hip disorder; the femoral head is separated from the femoral metaphysis. This disorder mainly occurs in those aged 10-15 years more frequently in males and its incidence rate is assumed to be one out of 10,000 persons ${ }^{17-20)}$. Approximately $78 \%$ of cases of this disorder occur in puberty, likely because this disease is associated with hormonal changes and growth spurts ${ }^{21)}$. Although the causes of SCFE have not yet been clearly established, hormonal disorders such as growth hormone $(\mathrm{GH})$ deficiency, hypothyroidism, rapid bone growth, obesity, and GH treatment are known to be associated with this disorder $^{22)}$.

There have been a few published reports regarding SCFE occurrence on or after cessation of GnRHa treatment ${ }^{7-10}$ ). GnRHa therapy may be implicated in reduced sex hormone exposure during the critical period of bone development, thereby contributing to the occurrence of SCFE. Otherwise, CPP itself can be a risk factor affecting SCFE because it causes rapid bone growth.

Table 1. Characteristics of patients with central precocious puberty and early onset puberty showing serious adverse drug reactions

\begin{tabular}{|c|c|c|c|c|c|c|c|c|}
\hline Patient No. & Age (yr) & Bone age (yr) & Sex & Adverse drug reaction & GnRHa depot & Interval (wk) & Onset of event & Allergic history \\
\hline 1 & 7.6 & 10.0 & $F$ & Sterile abscess & Leuprolide & 4 & 7th Injection & None \\
\hline 2 & 8.9 & 10.0 & $\mathrm{~F}$ & Sterile abscess & Leuprolide & 4 & 9th Injection & None \\
\hline \multirow[t]{2}{*}{3} & 9.0 & 11.0 & $\mathrm{~F}$ & Sterile abscess (1st) & Leuprolide & 4 & 5th Injection & None \\
\hline & & & & Sterile abscess (2nd) & Triptorelin & 4 & 1st Injection & \\
\hline 4 & 8.4 & 10.0 & $\mathrm{~F}$ & Anaphylaxis & Triptorelin & 4 & 6th Injection & None \\
\hline \multirow[t]{2}{*}{5} & 9.0 & 11.5 & $\mathrm{~F}$ & SCFE & Leuprolide & 4 & 5th Injection & None \\
\hline & & & & & Triptorelin & 4 & 6th Injection & \\
\hline
\end{tabular}

GnRHa, gonadotropin-releasing hormone agonist; SCFE, slipped capital femoral epiphysis. 
Table 2. Reports of luteinizing hormone releasing hormone analogs and "immune systems disorders" 1988-2010 of World Health Organization (97 countries) ${ }^{16)}$

\begin{tabular}{|c|c|c|}
\hline Drug & Reaction & No. of reports \\
\hline \multirow[t]{7}{*}{ Leuprolide } & Anaphylactic shock & 7 \\
\hline & Anaphylactic reaction ${ }^{\text {b) }}$ & 4 \\
\hline & Anaphylactoid reaction ${ }^{c)}$ & 23 \\
\hline & Serum sickness ${ }^{\mathrm{d})}$ & 6 \\
\hline & Multiple allergies & 1 \\
\hline & Hypersensitivity ${ }^{e}$ & 66 \\
\hline & Allergy to metals & 1 \\
\hline \multirow[t]{4}{*}{ Triptorelin } & Anaphylactic shock ${ }^{a)}$ & 3 \\
\hline & Anaphylactic reaction ${ }^{\text {b) }}$ & 2 \\
\hline & Anaphylactoid reaction ${ }^{c}$ & 1 \\
\hline & Hypersensitivity ${ }^{e}$ & 5 \\
\hline
\end{tabular}

Definitions conform the Netherlands Pharmacovigilance Center Lareb.

a) Hypersensitivity reaction with clinical signs in 2 or more organ

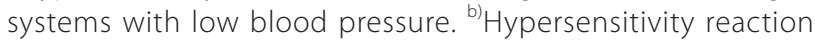
with clinical signs in 2 or more organ system without low

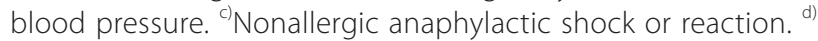
Serum sickness is a reaction similar to an allergy. Specifically, it is an immune system reaction to certain medications, injected

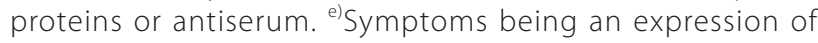
hypersensitivity.

Our fifth case was not obese and had no other hormonal disorder except early onset puberty. Most children with SCFE in other studies were different from ours in that GnRHa therapy was involved for a longer time because of earlier onset age of CPP. In case5, SCFE seems to occur coincidentally following GnRHa therapy. However, GnRHa treatment for CPP may be considered as a risk factor affecting the development of SCFE. Further studies seem to be necessary on the relationship between the occurrence of SCFE and GnRHa therapy.

In conclusion, in this study, sterile abscess formation occurred in $0.6 \%$ of CPP and early onset puberty patients with monthly depot GnRHa therapy. We also experienced the rare occurrence of one case of anaphylaxis, and another case of SCFE following GnRHa treatment in CPP and early onset puberty. GnRHa have been widely used globally and their drug safety has been well established. However, as the number of patients with GnRHa therapy is on the rise, potential adverse drug reactions can be increasing in number. Clinicians should be well acquainted with the potential adverse effects related to GnRHa therapy in CPP. Further studies are necessary to identify the mechanisms of development of potential adverse drug reactions.

\section{Conflict of interest}

No potential conflict of interest relevant to this article was reported.

\section{References}

1. Park MJ, Lee IS, Shin EK, Joung H, Cho SI. The timing of sexual maturation and secular trends of menarchial age in Korean adolescents. Korean J Pediatr 2006;49:610-6.

2. Sorensen K, Mouritsen A, Aksglaede L, Hagen CP, Mogensen SS, Juul A. Recent secular trends in pubertal timing: implications for evaluation and diagnosis of precocious puberty. Horm Res Paediatr 2012;77:137-45.

3. Mogensen SS, Aksglaede L, Mouritsen A, Sorensen K, Main KM, Gideon P, et al. Diagnostic work-up of 449 consecutive girls who were referred to be evaluated for precocious puberty. J Clin Endocrinol Metab 2011;96:1393-401.

4. Neely EK, Hintz RL, Parker B, Bachrach LK, Cohen P, Olney R, et al. Two-year results of treatment with depot leuprolide acetate for central precocious puberty. J Pediatr 1992;121:634-40.

5. Tonini G, Marinoni S, Forleo V, Rustico M. Local reactions to luteinizing hormone releasing hormone analog therapy. J Pediatr 1995;126:159-60.

6. Kim JM, Shin YL. Sterile abscess formation associated with two different forms of gonadotropin-releasing hormone agonist in central precocious puberty. Ann Pediatr Endocrinol Metab 2012;17:184-8.

7. Kempers MJ, Noordam C, Rouwe CW, Otten BJ. Can GnRH-agonist treatment cause slipped capital femoral epiphysis? J Pediatr Endocrinol Metab 2001;14:729-34.

8. Yamato F, Takaya J, Higashino H, Yamanouchi Y, Suehara $\mathrm{H}$, Kobayashi Y. Slipped capital femoral epiphysis during the treatment of precocious puberty with a gonadotropinreleasing hormone-agonist: aetiological considerations. Eur J Pediatr 2005;164:173-4.

9. van Puijenbroek E, Verhoef E, de Graaf L. Slipped capital femoral epiphyses associated with the withdrawal of a gonadotrophin releasing hormone. BMJ 2004;328:1353.

10. Inman M, Hursh BE, Mokashi A, Pinto T, Metzger DL, Cummings EA. Occurrence of slipped capital femoral epiphysis in children undergoing gonadotropin-releasing hormone agonist therapy for the treatment of central precocious puberty. Horm Res Paediatr 2013;80:64-8.

11. Sampson HA, Munoz-Furlong A, Campbell RL, Adkinson NF Jr, Bock SA, Branum A, et al. Second symposium on the definition and management of anaphylaxis: summary report: Second National Institute of Allergy and Infectious Disease/Food Allergy and Anaphylaxis Network symposium. J Allergy Clin Immunol 2006;117:391-7.

12. Manasco PK, Pescovitz OH, Blizzard RM. Local reactions to depot leuprolide therapy for central precocious puberty. J Pediatr 1993;123:334-5.

13. Johnson SR, Nolan RC, Grant MT, Price GJ, Siafarikas A, Bint L, et al. Sterile abscess formation associated with depot leuprorelin acetate therapy for central precocious puberty. J Paediatr Child Health 2012;48:E136-9.

14. Grant JP Jr, Levinson AW. Anaphylaxis to leuprolide acetate depot injection during treatment for prostate cancer. Clin Genitourin Cancer 2007;5:284-6.

15. Luchinger AB, Mijatovic V, Rustemeyer T, Hompes PG. Anaphylactic reaction to different gonadotropin-releasing 
hormone agonists for the treatment of endometriosis. Am J Med Sci 2011;341:240-2.

16. Uppsala Monitoring Centre. World Health Organization collaborating centre for international drug monitoring. Uppsala, SW: Uppsala Monitoring Centre, 2010.

17. Lehmann CL, Arons RR, Loder RT, Vitale MG. The epidemiology of slipped capital femoral epiphysis: an update. J Pediatr Orthop 2006;26:286-90.

18. Song KS, Oh CW, Lee HJ, Kim SD; Multicenter Study Committee of the Korean Pediatric Orthopedic Society. Epidemiology and demographics of slipped capital femoral epiphysis in Korea: a multicenter study by the Korean Pediatric Orthopedic Society. J Pediatr Orthop
2009;29:683-6.

19. Gholve PA, Cameron DB, Millis MB. Slipped capital femoral epiphysis update. Curr Opin Pediatr 2009;21:3945 .

20. Weiner D. Pathogenesis of slipped capital femoral epiphysis: current concepts. J Pediatr Orthop B 1996;5:67-73.

21. Douglas KK. Slipped capital femoral epiphysis. In: Morrissy RT, Weinstein SL, editors. Lovell and Winter's pediatrics. 4th ed. Philadelphia: Lippincott-Raven, 1996:993-1005.

22. Loder RT, Wittenberg B, DeSilva G. Slipped capital femoral epiphysis associated with endocrine disorders. J Pediatr Orthop 1995;15:349-56. 